\title{
LABOR MARKET REGULATION AND ITS CHARACTERISTICS: COMPARISON BETWEEN CZECH REPUBLIC AND AUSTRIA
}

\section{Martin Železník}

Faculty of Economics and Administration, Department of Economics, MU, Lipová 41a, Brno, zelko@mail.muni.cz

\begin{abstract}
In this paper, we are trying to compare the labor market regulation in the Czech Republic and Austria and its structural parameters that characterize the given labor markets. In order to do that, we estimate the New-Keynesian model with matching frictions and nominal wage rigidities. Labor market regulation is proxied by worker's bargaining power over the wage. This main parameter is moving inside the interval and express a share of the total surplus that arises from filling the vacancy. In fact it expresses the state of who gains more from the added value that the vacancy is filled (worker or employer). Results indicate that workers in Austria and the Czech Republic have almost the same bargaining power that arises from the labor market settings.
\end{abstract}

Key words: worker's bargaining power, labor market search, wage rigidities

JEL Classification: E24, J64

DOI: $10.2478 / \mathrm{v} 10135-011-0009-8$ 


\title{
LABOR MARKET REGULATION AND ITS CHARACTERISTICS: COMPARISON OF CZECH REPUBLIC AND AUSTRIA
}

\author{
Martin Železník ${ }^{1}$
}

\section{Introduction}

DSGE (Dynamic stochastic general equilibrium) models are based on the New Keynesian paradigm. We use them because they can include price and wage rigidities that are characteristic for the two countries considered. These rigidities establish a link between nominal and real activity. If the nominal prices stagger, fluctuations of nominal aggregates activate the fluctuations of real aggregates. The substantial work by Gali and Gertler (1999) had shown that the dynamic behavior of inflation is closely connected to a firm's marginal costs ${ }^{2}$ and that development of its dynamics depends on the functioning of the labor market.

In their work, Gali and Gertler (1999) assumed frictionless labor markets. According to empirical evidence from Bean (1994) and Flek and Vecernik (2005) we included labor market frictions because these works show us that labor markets in the Czech Republic and Austria are characterized by frictions that prevent competitive allocation of resources. Krause and Lubik (2007) show that these frictions enhance the idea of marginal cost in this New Keynesian model in a way that when costs of establishing a work relationship over and above the unit labor cost are included, they in principle adjust the dynamics of inflation.

The main contribution of this paper is the comparison of labor markets of the Czech Republic and Austria. We chose these two countries because they are geographic neighbors and their economies are connected. They have different levels of wages, so we want to find out if it is caused partially by the different regulation level on the labor market or just by the different level of productivity of workers. A regulation of the labor market can be caused by different sources, predominantly by flexibility of labor code, level of labor unionization and collective bargaining of wages but unfortunately, we are not able to distinguish between them and can not measure their individual influences.

We try to find out the level of regulation on the labor markets in these two countries. Our proxy parameter for this is the worker's bargaining power parameter because it can indicate who gains more from the created and filled vacancy, whether workers or employers. That can indicate if there is some space to make changes in the labor code to make acting on this market fairer for both sides.

Our understanding of this parameter is as follows. The labor market has its own characteristics according to the labor code. Somebody can think about the worker's bargaining power as an individual feature of the worker, but it is not the way we

\footnotetext{
${ }^{1}$ Faculty of Economics and Administration, Department of Economics, Masaryk University, Lipová 41a, Brno, zelko@mail.muni.cz

${ }^{2}$ Represented by unit labor cost
} 
understand it. We now introduce a short example. We can imagine the same working position and the same applicant with same ability in the two countries with different labor code. ${ }^{1}$ The process of bargaining the wage in the interview can be as follows: the applicant expresses the wage suitable for him/her and the employer gives him/her the offer, according to which the applicant decides whether to accept the job or not. Our image of this parameter is that the applicant in the country with more regulated labor code gets higher share of the total surplus that arises of filling the vacancy. This total surplus is defined by the shadow value of employment $\frac{W_{j t}^{*}}{\lambda_{t}}$ that is shown in eq.

The share that household gets is expressed by this parameter, so we picture it as an objective feature of regulation at the given labor market. The second contribution is that we estimate the structural parameters of the Czech and Austrian economy.

\section{Model}

This model is a combination of the search and matching framework according to Krause et al. (2008a) with the staggered wage setting mechanism stated in Thomas (2008). This world consists of households, firms which consist of a continuum of producers that are indexed by $j \in[0,1]$ and retailers, a monetary and fiscal authority. The following text introduces optimization problems that household and firm face, structure of the labor market, wage and hours bargaining according to Faccini, R., Millard, S. and Zanetti, F. (2010), who created this model. At the end of this part we provide a derivation of price and wage inflation and marginal costs. Only the main parts of the model are introduced. For detailed information, please refer to the original work.

\section{1. Households}

Economy is populated by a continuum of identical infinitely living households on the interval $[0,1]$. Members of the representative household perfectly insure each other against fluctuations in income. ${ }^{2}$ The representative household maximizes the expected utility function:

$$
E_{t} \sum_{t=0}^{\infty} \beta^{t} \zeta_{t}\left[\frac{\left(c_{t}-\varsigma C_{t-1}\right)^{1-\sigma}-1}{1-\sigma}-\chi_{t} \int_{0}^{1} n_{j t} \frac{h_{j t}^{1+\mu}}{1+\mu} \mathrm{d} j\right],
$$

where $\beta$ is the discount factor, $\zeta_{t}$ is the preference shock and $\chi_{t}$ is the labor supply shock. The first variable $c_{t}$ means consumption of the household at time $t$ and $C_{t-1}$ denotes aggregate consumption in period $t-1$. The next variable $n_{j t}$ represents the number of household members employed in a firm $j$, and $h_{j t}$ is the number of hours. The index of external habits is expressed as $\zeta$. The parameter $\sigma$ denotes the degree of

\footnotetext{
${ }^{1}$ Different minimum wage, different resignation period etc.

2 According to Andolfatto (1996).
} 
risk aversion and $\mu$ is the inverse of the Frish elasticity of labor supply. ${ }^{1}$ Consumption $c_{t}$ is a Dixit Stiglitz aggregator. ${ }^{2}$

The household confronts the following budget constraint:

$I_{t}+c_{t}+\frac{B_{t}}{p_{t}}=R_{t-1} \frac{B_{t-1}}{p_{t}}+\int_{0}^{1} \omega_{j t} n_{j t} h_{j t} \mathrm{~d} j+\left(1-n_{t}\right) b+r_{t}^{k} k_{t}+d_{t}+T_{t}$,

where the household's expenditures are investment $\left(I_{t}\right)$, consumption $\left(c_{t}\right)$ and the receipt of bonds $\left(B_{t} / p_{t}\right)$. On the other side the income stands, which consists of the stock of bonds $B_{t-1}$ from the previous period which gains a gross nominal interest rate $R_{t-1}$, the revenue from working in firm $j^{3}$ and the unemployed benefits $(b)$. Besides, the household gains income from renting capital $\left(k_{t}\right)$ to the firms at the rate $r_{t}^{k}$, the dividends from owning the firms $d_{t}$ and the net government $\operatorname{transfer} T_{t}$.

Thus the household chooses $c_{t}, B_{t}$ and $k_{t}$ to maximize its utility function (1) subject to the budget constraint (2) and the law of motion for capital,

$$
I_{t}=k_{t+1}-\left(1-\delta_{k}\right) k_{t},{ }^{4}
$$

When they substitute eq. (4) into eq. (3) and let $\lambda$ be the Lagrange multiplier on the budget constraint, they get the first order conditions.

$$
\begin{gathered}
\lambda_{t}=\zeta_{t}\left(c_{t}-\varsigma C_{t-1}\right)^{-\sigma}, \\
\lambda_{t}=\beta E_{t}\left[\lambda_{t+1} R_{t} / \pi_{t+1}\right], \\
\lambda_{t}=\beta E_{t} \lambda_{t+1}\left[r_{t+1}^{k}+\left(1-\delta_{k}\right)\right],
\end{gathered}
$$

where $\pi_{t+1}=p_{t+1} / p_{t}$. According to eq. (5), the Lagrange multiplier must equal the household's marginal utility of consumption. When they substitute eq. (5) into the eq. (6) and eq. (7), they get the Euler's equations that describe household's decision for consumption and capital.

\footnotetext{
${ }^{1}$ is defined as the wage elasticity of labor supply at a constant marginal utility of wealth ${ }^{2} c_{t}=\left(\int_{0}^{1} c_{t}(j)^{\left(\varepsilon_{t}-1\right) / \varepsilon_{t}} \mathrm{~d} j\right)^{\left(\varepsilon_{t}-1\right) / \varepsilon_{t}}$

3 expressed by the integral in equation (2)

${ }^{4}$ where $\delta_{k}$ is the rate of capital depreciation
} 


\section{2. Firms}

In this model they suppose producers and retailers. Workers are hired by producers in a frictional labor market and the capital is rent in a perfectly competitive market. They produce homogeneous goods and sell it to retailers in a perfectly competitive market. Then the goods are transformed by retailers to the differentiated goods that are sold to the consumers.

\section{Producers}

They manufacture $y_{j t}$ units of goods according to their constant returns to scale (CRS) ${ }^{1}$ production function $y_{j t}=A_{t}\left(n_{j t} h_{j t}\right)^{\alpha} k_{j t}^{1-\alpha}$, where $A_{t}$ is a variable catching shocks to total factor productivity.

The cost of opening a vacancy is $C\left(v_{j t}\right)=a v_{j t}^{\varepsilon_{c}}$, where $a>0$ is a scaling factor and $\varepsilon_{c}>1$ is the elasticity of hiring costs with respect to vacancies. ${ }^{2}$ Variable $v_{j t}$ means number of vacancies opened in time $t$ by one firm.

The firm chooses $v_{j t}, n_{j t}$ and $k_{j t+1}$, so it maximizes the present value of its future discounted profits:

$$
\max E_{t} \sum_{s=0}^{\infty} \beta^{s} \frac{\lambda_{t+s}}{\lambda_{t}}\left[\varphi_{t+s} y_{t+s}-\omega_{j t+s} n_{j t+s} h_{j t+s}-C\left(v_{j t+s}\right)-k_{j t+s} r_{t+s}^{k}\right],^{3}
$$

subject to the production function and the law of motion for employment:

$$
n_{j t}=(1-\rho) n_{j t-1}+v_{j t} q\left(\theta_{t}\right) .
$$

Now, they show the first order conditions with respect to $k_{j t+1}, v_{j t}$ and $n_{j t}$ :

$$
\begin{gathered}
r_{t}^{k}=\varphi_{t}(1-\alpha) A_{t}\left(n_{j t} h_{j t}\right)^{\alpha} k_{j t}^{-\alpha}, \\
\frac{C^{\prime}\left(v_{j t}\right)}{q\left(\theta_{t}\right)}=J_{j t}, \\
J_{j t}=\varphi_{t} \alpha A_{t}\left(n_{j t} h_{j t}\right)^{\alpha-1} k_{j t}^{1-\alpha} h_{j t}-\omega_{j t} h_{j t}+\beta(1-\rho) E_{t} \frac{\lambda_{t+1}}{\lambda_{t}} J_{j t+1} .
\end{gathered}
$$

\footnotetext{
${ }^{1} \mathrm{CRS}$ imply that all firms have the same capital/labor ratio $k_{j t} / n_{j t} h_{j t}=k_{t} / n_{t} h_{t}$ for all $\mathrm{j}$

${ }^{2}$ vacancy function is assumed to be convex because we want it to be able to produce an equilibrium, where all firms post vacancies

${ }^{3}$ because households own the firms, future profits are discounted by $\beta^{s} \lambda_{t+s} / \lambda_{t}$ and $\varphi_{t}$ means marginal costs
} 
Eq. (9) shows that returns to capital are equal to the marginal revenue product. Eq. (10) means that cost of filling the vacancy for the firm times average vacancy duration must be identical to the shadow value of employment $J_{j t}$ and Eq. (11) shows that $J_{j t}$ equals profits in the current period. ${ }^{1}$

By substituting Eq.(10) into Eq.(11), they get the standard job creation condition:

$$
\frac{C^{\prime}\left(v_{j t}\right)}{q\left(\theta_{t}\right)}=\varphi_{t} \alpha A_{t}\left(n_{j t} h_{j t}\right)^{\alpha-1} k_{j t}^{1-\alpha} h_{j t}-\omega_{j t} h_{j t}+\beta(1-\rho) E_{t} \frac{\lambda_{t+1}}{\lambda_{t}} \frac{C^{\prime}\left(v_{j t+1}\right)}{q\left(\theta_{t+1}\right)} \text {. }
$$

\section{Retailers}

They transform homogeneous goods created by the producers to differentiated goods. They face monopolistic competition that implies that each retailer confronts demand for its own product

$$
c_{j t}=\left(\frac{p_{j t}}{p_{t}}\right)^{-\varepsilon_{t}} c_{t}
$$

where $c_{t}$ is the aggregate demand. They produce $c_{j t}$ pieces of output as they use the same amount of inputs. They use price stickiness ' $a$ la Calvo (1983), according to that random part of firms, $0<\delta_{p}<1$ are not allowed to determine their price. $p_{j t}$ is the price that an individual firm sets for their product and $p_{t}$ is the aggregate price level.

Solution to their problem is to set the $p_{j t}$ in order to maximize:

$$
\max E_{t} \sum_{s=0}^{\infty} \delta_{p}^{s} \beta^{s} \frac{\lambda_{t+s}}{\lambda_{t}}\left[\frac{p_{j t}}{p_{t+s}}-\varphi_{t+s}\right] c_{j t+s},
$$

subject to the demand function. So now they can deduce the optimal pricing decision:

$$
E_{t} \sum_{s=0}^{\infty} \delta_{p}^{s} \beta^{s} \frac{\lambda_{t+s}}{\lambda_{t}}\left(\frac{p_{t}^{*}}{p_{t+s}}-\frac{\varepsilon_{t}}{\varepsilon_{t}-1} \varphi_{t+s}\right)=0
$$

where $p_{t}^{*}$ is the optimal price which is chosen by the firm that is allowed to renegotiate the price at time $t$. This means that firms which can renegotiate their price, set it at the

\footnotetext{
${ }^{1}$ marginal revenue product of employment minus wage costs plus the continuation value
} 
optimal price level such that the time-varying mark-up is equal to $\varepsilon_{t} /\left(\varepsilon_{t}-1\right)$. Because the firms are selected randomly to change the price, the law of motion for the aggregate price level is:

$$
p_{t}^{1-\varepsilon_{t}}=\delta_{p} p_{t-1}^{1-\varepsilon_{t}}+\left(1-\delta_{p}\right)\left(p_{t}^{*}\right)^{1-\varepsilon_{t}}
$$

\section{3. Labor market}

In this model, they establish now the standard matching function $M\left(U_{t}, V_{t}\right)=m U_{t}^{\xi} V_{t}^{1-\xi}$ which means the aggregate flow of hires in a period. $U_{t}$ reflects aggregate unemployment and $V_{t}$ aggregate vacancies, $m>0$ is a matching efficiency and $0<\xi<1$ expresses the elasticity of the matching function with respect to unemployment. Vacancies are filled during periods according to probability $q\left(\theta_{t}\right)=M_{t} / V_{t}$, where $\theta_{t}=V_{t} / U_{t}$ means labor market tightness. ${ }^{1}$

Aggregate employment evolves according to:

$$
N_{t}=(1-\rho) N_{t-1}+M_{t}
$$

where $N_{t}$ and $M_{t}$ represent the number of workers employed and hired in period $t$ and $0<\rho<1$ is the probability that workers lose their job.

They assume, as in Blanchard and Gali (2006), a full participation in the labor market such as:

$$
U_{t}=1-(1-\rho) N_{t-1}+M_{t}
$$

Let $W_{j t}^{E}$ and $W_{j t}^{U}$ denote the marginal value of being employed and unemployed. The marginal value of employment at a firm $j, W_{j t}^{E}$, is given by:

$W_{j t}^{E}=\lambda_{t} \omega_{j t} h_{j t}-\zeta_{t} \chi_{t} \frac{h_{j t}^{1+\mu}}{1+\mu}+\beta E_{t} \lambda_{t+1}\left[\rho W_{t+1}^{U}+(1-\rho) W_{j t+1}^{E}\right]$,

which shows that the $W_{j t}^{E}$ is given by the real wage minus the disutility of work plus the expected-discounted value from being either employed or unemployed in the following period.

The marginal value of unemployment, $W_{t}^{U}$

\footnotetext{
${ }^{1} \mathrm{CRS}$ in the matching function stands for workers finding a job with probability $\theta_{t} q\left(\theta_{t}\right)$
} 


$$
W_{t}^{U}=\lambda_{t} b+\beta E_{t} \lambda_{t+1}\left[\left(1-\theta_{t+1} q\left(\theta_{t+1}\right)\right) W_{t+1}^{U}+\theta_{t+1} q\left(\theta_{t+1}\right) \hat{W}_{t+1}^{E}\right]{ }^{1}
$$

means that the marginal value of unemployment is the sum of unemployment benefits plus the expected-discounted value from being employed or unemployed in the period $t+1$. They can now determine the household's net value of employment at firm $j$, which can be calculated as $W_{j t}^{E}-W_{t}^{U}$, denoted by $W_{j t}$, as:

$W_{j t}=\lambda_{t} \omega_{j t} h_{j t}-\lambda_{t} b-\zeta_{t} \chi_{t} \frac{h_{j t}^{1+\mu}}{1+\mu}+\beta E_{t} \lambda_{t+1}(1-\rho)\left[W_{j t+1}-\theta_{t+1} q\left(\theta_{t+1}\right) \hat{W}_{t+1}\right]$,

where $E_{t} \hat{W}_{t+1}=\int_{0}^{1} W_{j t+1} \mathrm{~d} j$.

\section{Wage bargaining}

They suppose staggered wage negotiations which means that only a part of firms $0<\delta_{w}<1$ can renegotiate on wages. In accordance with Thomas (2008), they assume that the renegotiating firm sets the wage according to the sharing rule:

$$
\eta J_{j t}^{*}=(1-\eta) \frac{W_{j t}^{*}}{\lambda_{t}}
$$

where $0<\eta<1$ is the bargaining power of the worker and the superscript means those workers and firms, who renegotiate. ${ }^{2}$ This is the main investigating field we focus on, because it determines who obtains a bigger fraction of the total surplus equal to their bargaining power.

With staggered wage negotiations, the shadow value of employment at firm $j$ to the household that can renegotiate, they can rewrite it from equation (21) as follows:

$$
\frac{W_{j t}^{*}}{\lambda_{t}}=\omega_{j t}^{*} h_{j t}-\tilde{\omega}_{j t}+\beta E_{t} \frac{\lambda_{t+1}}{\lambda_{t}}(1-\rho)\left[\delta_{w} \frac{W_{j t+1 \mid t}}{\lambda_{t+1}}-\left(1-\delta_{w}\right) \frac{W_{j t+1}^{*}}{\lambda_{t+1}}\right],
$$

where the opportunity cost of holding the job for the worker, $\widetilde{\omega}_{j t}$ is:

\footnotetext{
${ }^{1}$ where $E_{t} \hat{W}_{t+1}^{E}=\int_{0}^{1} W_{j t+1}^{E} \mathrm{~d} j$ is the expected value of employment outside the firm in $t+1$.

${ }^{2}$ Notice that this is different from Nash Bargaining
} 


$$
\tilde{\omega}_{j t}=b+\frac{\zeta_{t} \chi_{t}}{\lambda_{t}} \frac{h_{j t}^{1+\mu}}{1+\mu}+\beta E_{t} \frac{\lambda_{t+1}}{\lambda_{t}}(1-\rho) \theta_{t+1} q\left(\theta_{t+1}\right) \frac{\hat{W}_{t+1}}{\lambda_{t}}
$$

The eq. (23) shows us the net value of employment to the household that is conditioned by wage renegotiated at time $t$. The net flow income from employment is $\omega_{j t}^{*} h_{j t}-\widetilde{\omega}_{j t}$ plus the continuation value. The last term in the brackets means the sum of the marginal discounted value of employment in $t+1$ that is conditioned on the wage at time $t$ for the firm that does not renegotiate with probability $\delta_{w}$ and the value of employment in $t+1$ that is conditioned on a renegotiation with probability $1-\delta_{w}$. Now they look at the shadow value of employment to the renegotiating firm $j$, similarly:

$$
J_{j t}^{*}=\bar{\omega}_{j t}-\omega_{j t}^{*} h_{j t}+(1-\rho) E_{t} \frac{\lambda_{t+1}}{\lambda_{t}}\left[\delta_{w} J_{j t+1 \mid t}+\left(1-\delta_{w}\right) \frac{W_{j t+1}^{*}}{\lambda_{t+1}}\right],
$$

where $\bar{\omega}_{j t}=\varphi_{t} m p l_{t} h_{j t}$ means the marginal revenue product. Eq. (24) shows us the net flow value of the match $\bar{\omega}_{j t}-\omega_{j t}^{*} h_{j t}$ plus the continuation value, which equals the marginal value of employment in $t+1$ conditional on the wage at time $t$ with probability $\delta_{w}$ and the marginal value conditioned on a wage renegotiation with probability $\left(1-\delta_{w}\right)$. Now by iterating previous two equations forward, it is possible to rewrite them and then by using the sharing rule from eq. (22):

$$
E_{t} \sum_{s=0}^{\infty} \beta^{s} \frac{\lambda_{t+s}}{\lambda_{t}}(1-\rho)^{s} \delta_{w}^{s}\left(\omega_{j t}^{*} h_{j t+s}-\omega_{t+s}^{t a r}\right)=0
$$

where $\omega_{j t+s}^{t a r}=\eta \bar{\omega}_{j t+s}+(1-\eta) \widetilde{\omega}_{j t+s}$ is the total wage payment to the worker which is agreeable for both parties if wages are fully flexible. By substituting for $\overline{\boldsymbol{\omega}}_{j t+s}$ and $\widetilde{\omega}_{j t+s}$ they get the target real wage bill which can be written as:

$\omega_{j t+s}^{a r}=\eta \varphi_{t} m p l_{t} h_{j t}+(1-\eta)\left[b+\frac{\zeta_{t} \chi_{t}}{\lambda_{t}} \frac{h_{j t}^{1+\mu}}{1+\mu}+\beta E_{t} \frac{\lambda_{t+1}}{\lambda_{t}}(1-\rho) \theta_{t+1} q\left(\theta_{t+1}\right) \frac{\hat{W}_{t+1}}{\lambda_{t}}\right]$. 
This equation is standard in the search and matching literature. The target real wage bill is defined as a weighted average between the marginal revenue product of the worker and the opportunity cost of holding a job at the level of hours worked $h_{j t}$. As the renegotiating firms are randomly chosen, they can write the law of motion for the aggregate wage:

$$
\omega_{t}=\delta_{w} \omega_{t-1}+\left(1-\delta_{w}\right) \omega_{t}^{*}
$$

\section{Hours bargaining}

Their assumption in this part is that hours and wages are bargained simultaneously and that bargaining on hours is efficient, which means that hours satisfy the Nash bargaining criterion:

$$
h_{j t}=\operatorname{argmax}\left(\frac{W_{j t}^{*}}{\lambda_{t}}\right)^{\eta}\left(J_{j t}^{*}\right)^{(1-\eta)} .
$$

By using the sharing rule, the $\mathrm{FOC}$ is:

$$
\frac{\chi_{t} \zeta_{t}}{\lambda_{t}} h_{j t}^{\mu}=\varphi_{t} A_{t} \alpha^{2} n_{j t}^{\alpha-1} h_{j t}^{\alpha-1} k_{j t}^{1-\alpha}
$$

On the left hand side of the equation, there is the marginal rate of substitution of hours that equals the marginal product of hours. Marginal return to the labor input is equalized across firms at equilibrium, which means that household members employed in different firms work the same amount of hours, i. e., $h_{j t}=h_{t}$. Now they solve the FOC for hours:

$$
h_{j t}=\eta\left(\frac{\varphi_{t} A_{t} \alpha^{2} n_{j t}^{\alpha-1} k_{j t}^{1-\alpha}}{\chi_{t} \zeta_{t}} \lambda_{t}\right)^{\frac{1}{1+\mu-\alpha}}
$$

\section{4. Price and wage inflation}

According to Calvo (1983), using the optimal price decision, eq. (15), and the law of motion for the aggregate price level, eq. (16), the standard New Keynesian Phillips Curve is derived:

${ }^{1}$ where $\omega_{t}=\int_{0}^{1} \omega_{j t} \mathrm{~d} j$ 


$$
\pi_{t}=k_{p}\left(\hat{\varphi}_{t}+\varepsilon_{t}\right)+\beta E_{t} \pi_{t+1},
$$

where hat superscript means the variable's deviation from its steady-state, and the coefficient $k_{p}$ is equal to:

$$
k_{p} \equiv \frac{\left(1-\beta \delta_{p}\right)\left(1-\delta_{p}\right)}{\delta_{p}} .
$$

Similarly according to Thomas (2008), using eq. (26) and eq. (28) they get the equation for the wage inflation:

$$
\pi_{w t}=k_{w}\left[\hat{\omega}_{t}^{t a r}-\left(\hat{\omega}_{t}+\hat{h}_{t}\right)\right]+\beta(1-\rho) E_{t} \pi_{w t+1},
$$

where the coefficient $k_{w}$ is equal to:

$$
k_{w} \equiv \frac{\left[1-\beta(1-\rho) \delta_{w}\right]\left(1-\delta_{w}\right)}{\delta_{w}} .
$$

This stands for that wage inflation depending on the gap between the actual and the target real wage bill. It means that inflation can occur whenever the real wage bill is below target, that is whenever the wage bill is below the level that would prevail if wages were perfectly flexible.

\section{5. Closing the model}

The monetary authority determines the interest rate according to the Taylor rule:

$$
\frac{R_{t}}{R^{*}}=\left(\frac{R_{t-1}}{R^{*}}\right)^{\rho_{r}}\left[\left(\frac{\pi_{t}}{\pi^{*}}\right)^{r_{\pi}}\left(\frac{y_{t}}{y^{*}}\right)^{r_{y}}\right]^{1-\rho_{r}} \varepsilon_{t}^{R},
$$

In this case, the asterisk superscript means the steady state value of the variable. The parameter $\rho_{r}$ is the interest rate smoothing, and $r_{y}$ and $r_{\pi}$ determine the response of the monetary authority to deviations of output and inflation from their steady state value. At the end the term $\varepsilon_{t}^{R}$ means an i.i.d. monetary policy shock.

The fiscal authority is assumed to run a balanced budget:

$$
\frac{B_{t}}{p_{t}}=R_{t-1} \frac{B_{t-1}}{p_{t}}+T_{t}+b\left(1-n_{t}\right) .
$$




\section{6. Marginal Costs}

In this part it is shown a comparison of specification of marginal costs against the alternative formulations in literature. This is important for understanding of the model properties, the results and findings in the next section. According to Trigari (2006), whenever firms post vacancies at a time $t$ in order to acquire the employment in the following period, the matching model with efficient bargaining on hours has not got the transmission channel from wages to prices because the real marginal cost is independent of wages. The intuition behind is clear. Current hires affect next period employment, so in current period firms can change production only by adjusting hours. This indicates that the marginal cost of production depends only on hours. They have efficient bargaining over the hours worked, so the number of hours worked is determined by the marginal rate of substitution between consumption and leisure and the marginal product of labor and therefore, it is independent of wages. This implies that wages are irrelevant for marginal costs, but this channel needs to be restored.

A wage channel will be restored and simultaneously the efficient Nash bargaining will be preserved. It can be done by changing the timing assumption of the matching function. Firms are allowed to control employment at time $t$ by choosing vacancies in the same period (described in eq. 8). Now, the cost of increasing production at the margin depends on the cost of hiring an additional worker, which is represented by the wage paid to the new hire. I can be shown by solving the job creation condition in equation (11) for marginal costs $\varphi_{t}$ :

$$
\varphi_{t}=\frac{\omega_{t} h_{t}}{m p e_{t}}+\frac{J_{t}-\beta E_{t} \frac{\lambda_{t+1}}{\lambda_{t}}(1-\rho) J_{j t+1}}{m p e_{t}},
$$

where $m p e_{t}=A_{t} \alpha\left(n_{j t} h_{j t}\right)^{\alpha-1} k_{j t}^{1-\alpha} h_{j t}$ means the marginal product of employment. This equation shows that real marginal costs are equal to the sum of the unit labor cost and additional term related to matching frictions. If they have the shadow value of employment $J_{t}$ which means the expected hiring cost, the second term on the right hand side of eq. (38) can be interpreted as the expected change in search costs, that depends according the eq.(10) on the expected value of labor market tightness in the next period relative to the current period.

\section{Estimation}

We estimate this model with Bayesian methods. First, we log linearize it around the deterministic steady state. We use matlab toolbox Dynare 4.1.1 that solves the model and applies the Kalman filter to evaluate the likelihood function of the observable variables. We combine the likelihood function and the prior distribution of the parameters in order to obtain posterior distributions. The posterior kernel is simulated numerically using the Metropolis-Hastings algorithm. First, we discuss the data and the priors used in the estimation. 


\section{1. Priors and data}

We estimate this model over the period 1998Q1-2010Q1 using five shocks and five data series gained from Eurostat. We use quarterly observations of real output scaled by the labor force. Inflation is measured as percentage changes of the GDP deflator. Average hours, employment in heads and bank rates are the next series. ${ }^{1}$ All series, with the exception of the Bank rate, are passed through a Hodrick-Prescott filter with smoothing parameter 1600 .

We used five shocks in the model and they are subsequent: preference shock, a mark-up shock, a labor supply shock, a technology shock and a monetary policy shock. All shocks, with the exception of monetary policy shock, are supposed to follow a firstorder autoregressive process with i.i.d. normal error terms such as $\ln \kappa_{t+1}=\rho_{\kappa} \ln \kappa_{t}+v_{t}$, where the shock $\kappa \in\{\zeta, \chi, \varepsilon, A\}, 0<\rho_{\kappa}<1$ and $v_{t} \sim N\left(0, \sigma_{\kappa}\right)$. Monetary policy shock $\varepsilon_{t}^{R}$ is i.i.d.

Now we are going to deal with the parameters. Some of them are fixed, while the other ones are estimated.

\section{The Czech Republic}

We start by defining the fixed parameters. The discount factor $\beta$ is set at 0.99 which implies the real interest rate of $4 \%{ }^{2}$ Capital depreciation $\delta_{k}$ is set at 0.025 in order to match the average annual rate of capital destruction of $10 \%$ and $\alpha$ at 0.66 to match the labor share. The habits parameter, $\zeta$, and the elasticity of the vacancy cost function, $\varepsilon_{c}$ are also fixed. Subsequently, the habits parameter is calibrated at 0.75 according to Hlousek (2008) and the elasticity of the vacancy cost function is set at 1.1 that is relatively close to the standard assumption of linear adjustment costs, and satisfies the assumption of convexity. Table 1 summarizes the values of the fixed parameters for the Czech Republic.

The remaining parameters are all estimated. We use Bayesian techniques for estimation so we use a prior mean, standard deviation and prior distribution information to improve the estimates. It has become a custom that we use the beta distribution for parameters that take sensible values between zero and one, the gamma distribution for coefficients restricted to be positive and the inverse gamma distribution for the shock variances. Table 2 and 3 show priors, posterior estimates and $90 \%$ confidence intervals.

The relative risk aversion, $\sigma$, is set to 1 according Remo (2007). The inverse Frish elasticity, $\mu$, is set to 1.9 according the the previous work. The matching function elasticity, $\xi$, for the Czech economy is set to 0.42, as estimated by Burda (1993). The constant of the matching function, $m$, is set to 1 . Unemployment benefits, $b$, is set to

\footnotetext{
${ }^{1}$ in our case we use the non-risk bank rates of the state's bonds that are used for the convergence purposes

$\beta=\frac{1}{1+r}$, where $r$ is the real interest rate
} 
match a replacement rate of 0.53 according to estimates of OECD for the Czech Republic. When $b$ is high, it means that the value of a job to the worker is almost the same as the value of being unemployed. The job destruction rate, $\rho$, is set to 0.03 as shown in Faggio (2006). The Calvo wage parameter, $\delta_{w}$, is set according to Hlousek (2009) to 0.75 . The Calvo price parameter $\delta_{p}$ is set to 0.6 according to Herber (2009). The elasticity of demand, $\mathcal{E}$, is set to 11 . This value is shown in Britton, Larsen and Small (2000) and implies a steady state mark-up of $10 \%$. The main parameter, the worker bargaining power, $\eta$, is set to the standard value 0.5 .

Now, we choose the prior mean of the Taylor rule response to inflation, $r_{\pi}$. Its value is 1.5 , which is the standard value in the literature. The response to output $r_{y}=0.5$ is set a little bit higher than its usual value. The prior mean of the interest rate smoothing parameter is set to 0.5 .

\section{Austria}

The fixed parameters are calibrated almost in the same way. The discount factor, $\beta$, is set to 0.988 in order to imply the steady state real interest rate of approximately $5 \%$ annually. The capital depreciation rate, $\delta_{k}$, is set to 0.02 and the habit persistence, $\varsigma$, is set to 0.5. All these fixed parameters are set according to Breuss and Rabitsch (2008).

Now we are going to introduce the prior mean calibration of estimated parameters. We concentrate on the different calibration of prior means for individual parameters. The inverse Frish elasticity, $\mu$, is set to 2 according to Christoffel et al. (2008). The prior mean of the matching function elasticity, $\xi$, is set to 0.6 according the Christo-ffel et al. (2009). The unemployment benefits, $b$, is set to match a replacement ratio 0.5 as in Nickell (1997). The prior means for the Calvo wage and price parameter are set to 0.6 according to Breuss and Rabitsch (2008). Elasticity of demand is set classically to match the mark-up of $10 \%$ and for that we set prior mean at 11 . According to the previous work we set the priors means of the Taylor rule parameters, where these priors were used for the time period when Austria was a member of monetary union, which corresponds to our data set. The priors are $r_{y}$, that is the Taylor rule response to output is set at 0.2 and $r_{\pi}$ is set at 1.7 and Taylor rule inertia is set to 0.85 .

The prior settings of shock parameters are as follows. According to Breuss and Rabitsch (2008) again, we set these priors at following values. The prior means of the persistence parameters, $\rho_{\chi}, \rho_{\zeta}, \rho_{\varepsilon}$ and $\rho_{a}$ are all set at 0.8 and their standard errors are set as shows the Table 6. The priors for shock parameters in Austria are set differently and higher than for the Czech Republic because according to Breuss and Rabitsch (2008), there is the reason to think that these shocks are those mainly responsible for driving the cyclical variations in the Austrian macroeconomic time series. 


\section{2. Parameter estimates}

\section{The Czech Republic}

Table 2 shows posterior mean of the structural parameters and $90 \%$ confidence intervals. The first parameter to comment on is the parameter of unemployment benefits that equals to 0.556 , which is nearly the same as its prior.

The estimate of the inverse Frish elasticity of labor supply of 2.1586 is close to its prior, too. The estimated value of the elasticity of labor supply is therefore approximately 0.46 and can be interpreted in such a way that $1 \%$ increase of the real wage brings only $0.46 \%$ increase of the labor supply. The reasons for such a low value could be credited to low labor mobility, long run unemployment and an increase of labor productivity accompanying the rise in real wages, as argued in Musil and Vasicek (2006).

The posterior for the constant of the matching function, $m$, is 1.0764 and the constant of the vacancy cost function, $a$, is 5.3820. They are almost similar to their prior means. The posterior means of $\rho$, the rate of job separations, is 0.0512 , which is almost similar to its prior, too, and implies almost the same unemployment rate as our baseline calibration.

The posterior mean of the matching function elasticity, $\xi$, is equal to 0.2874 , that is lower than its prior. This estimate is lower than the standard value 0.5 used in US studies, where the number of new hires depends equally on the number of unemployed people and on the vacancies posted. This low estimate suggests that the number of new hires depends more on the number of vacancies posted rather than on the number of unemployed workers.

The posterior means of the Calvo parameters that shows the frequency of wage and price adjustments and share of firms that do not optimize, $\delta_{w}$ and $\delta_{p}$, are 0.7732 and 0.6021 , respectively. The first value implies an average frequency of wage negotiations in this model at 4 and a half quarters ${ }^{1}$ and shows that only $20 \%$ of firms renegotiate their wage contracts every period. ${ }^{2}$ The second value shows that the average frequency of price adjustment is 2 and a half quarters and almost $40 \%$ of firms adjusts their prices every period.

Now let us carry on with the posterior means in the Taylor rule. The posterior of the interest rate response to inflation, $r_{\pi}$, is equal to 1.5234 , which indicates a strong response to inflation and the degree of interest rate smoothing, $\rho_{r}$, is 0.5313 and suggests a moderate degree of interest rate inertia. The high estimate for $r_{y}$, equal to

${ }^{1}$ the average duration of the wage contracts is $\frac{1}{\left(1-\delta_{w}\right)}$

2 every three months in this case, because we use quarterly data 
0.6867, suggests a strong response to output, which is quite surprising and larger than the usual value of 0.125 .

Table 3 shows estimates of the shock parameters. The posterior means of the persistence parameters, $\rho_{\chi}$ and $\rho_{\zeta}$, equal to 0.9995 and 0.9999 , respectively. The other two posterior means for, $\rho_{\varepsilon}$ and $\rho_{a}$, are 0.9952 and 0.9637 . All of them show that they are highly persistent. The posterior means of $\sigma_{\zeta}, \sigma_{a}$ and $\sigma_{\varepsilon}$ equal to $0.0017,0.0234$ and 0.0269 respectively. They have almost similar magnitude, while the estimates of $\sigma_{\chi}$ and $\sigma_{\varepsilon}$, equal to 0.1684 and 0.0701 and show a higher variance of labor supply and mark-up shock. The persistence of the preference shock is close to unity that can suggest that in spite of the wage rigidities, the model has a weak internal mechanism of propagation and requires persistence in the shock in order to match inflation persistence.

The main parameter of our estimate is $\eta$ because it represents worker's bargaining power. Our estimate is close to its prior and is equal to 0.5011 , which means that the $1-\eta$ share of the total surplus arising from filling the vacancy is gained by the worker. So it shows a very light dominance of employers in Czech Republic over the worker.

\section{Austria}

Table 4 shows posterior means of the structural parameters and $90 \%$ confidence intervals. the first parameter to comment on is the unemployment benefits that equal to 0.5015 , which is nearly the same as its prior. This system is generous by U.S. standards, where this parameter is 0.5 , too, but the difference is in the duration. In the U. S. it is 6 months while in Austria 2 years.

Our estimate of inverse Frish elasticity 2.2313 is quite higher than the estimates in other works. For example Breuss and Rabitsch (2008) estimated Austria's structural parameters in two periods. Pre-EMU period and EMU period correspond to our data set. Their estimate was 1.29 , but their model was an adequately different two-country model. The elasticity of labor supply is then 0.448 .

The posterior for the constant of the matching function, $m$, is 1.0219 and the constant of the vacancy cost function, $a$, is 4.5529 . While the first one is almost similar to its prior mean, the other is quite different. The posterior means of $\rho$, the rate of job destruction, is 0.0464, which is a little bit higher and almost the same in the Czech Republic.

The posterior mean of the matching function elasticity, $\xi$, is equal to 0.4620 , which is lower than its prior, but in comparison to the Czech Republic it seems that in Austria the number of new hires depends almost equally on the number of vacancies and the number of unemployed people.

The Calvo wage parameter $d_{w}$ is 0.6079 and implies an average frequency of wage negotiations at 2 and half quarters. The second Calvo parameter, the price Calvo para- 
meter, 0.5880, shows that the average frequency of price adjustment is almost the same as in the previous case.

Now we will focus on the posterior means in the Taylor rule. The posterior of the interest rate response to inflation, $r_{\pi}$, is equal to 1.6954 , which indicates even stronger response to inflation than in the Czech Republic. The degree of interest rate smoothing, $\rho_{r}$, is 0.8126 , which is close to its prior that is standard in the literature. The high estimate for $r_{y}$, equal to 0.5577 , suggests a strong response to the output, but lower than in the Czech Republic.

Table 5 shows estimates of the shock parameters for Austria. The posterior means of the persistence parameters, $\rho_{\chi}$ and $\rho_{\zeta}$, equal to 0.9390 and 0.8262 , respectively. The other two posterior means for, $\rho_{\varepsilon}$ and $\rho_{a}$, are 0.9797 and 0.6355 . The first three of them show that they are highly persistent. The posterior means of $\sigma_{\varepsilon}, \sigma_{a}$ and $\sigma_{\varepsilon}$ equal to $0.1098,0.1289$ and 0.1295 respectively. They have almost similar magnitude, while the estimates of $\sigma_{\chi}$ and $\sigma_{\zeta}$, equal to 0.3968 and 0.2222 show a higher variance of labor supply and preference shock. The persistence of the mark-up shock is close to unity, which can suggest that in spite of the wage rigidities the model has a weak internal mechanism of propagation and in order to match inflation persistence, it requires persistence in the shock, which is the same like in the case of the Czech Republic. The shock parameters estimates do not indicate higher influence of shocks for the cyclical variations in the macroeconomic time series as it was assumed, which is in contrast of results of the work of Breuss and Rabitsch (2008).

The main parameter, $\eta$, is close to its prior and is equal to 0.5040 , which means that the $1-\eta$ share of the total surplus, that arises from filling the vacancy gains of the worker. So it shows a very light dominance of employers in Austria over the worker. Therefore, the results regarding this parameter show that the labour market in the Czech Republic is relatively close to the Austrian one in the labor market regulation.

\section{3. Impulse response function}

This part of the work will now provide a short by-product of our analyses and show one example although it is not a main part of our article. Impulse response for the technology shock for the Czech Republic can be found in the Figure 1. The positive technology shock increases possibilities of the economy, so it causes the growth of the potential output. Thanks to an increased productivity, the real marginal costs are decreasing, which causes inflation decrease. Lower inflation results in a lower nominal interest rate that endorses consumption and investment. In the presence of nominal wage rigidities, the real wages increases. It is perceptible that vacancies, employment and labor market tightness fall in the presence of sticky wages. Technology shock increases the marginal product of labor and the real wage. The difference between these two is the main feature that motivates firms for posting vacancies as shown in eq. (12). The real wages increase more than the marginal product of labor with sticky wages and remain boosted during the process of adjustment. 


\section{Conclusion}

We estimated a New Keynesian model with labor market frictions on the data of the Czech Republic and Austria because these countries show the rigidities on labor market from the microeconomic data and from the works mentioned in the introduction. In a search and matching model like this one, the marginal cost depends on the unit labor cost and on the frictional costs of searching.

Our main goal was to estimate important structural parameters including the main one, the worker's bargaining power that represents the regulative character of the labor codes of these two economies, and to compare them to each other. Our findings were close to the prior information about the estimated structural parameters and show us the main characteristics of the labor market in these two countries.

The labor market is working quite fair according to our estimate of the worker's bargaining power. None of the negotiating sides have the decisive power to gain more from the total surplus that arise when the vacancy is fulfilled. So our analyses have proven that the different level of wages in these countries is mainly caused by the higher productivity of workers rather than by regulation of the labor market.

\section{References}

ANDOLFATTO, D. (1996). Business Cycles and Labor Market Search, American Economic Review. 86, Pp. 112-132.

BEAN, C. R. (1994). European unemployment: a survey. Journal of Economic Literature. Volume 32, Pp. 573-619.

BLANCHARD, O. J., GALI, J. (2006). A new Keynesian model with unemployment, National Bank of Belgium Research Series No. 92.

BREUSS, F. and RABITSCH, K. (2009). An estimated two-country DSGE model of Austria and the Euro Area. Empirica. Volume 36, pp. 123-158. DOI: 10.1007/s10663008-9095-y

BRITTON, E., LARSEN, J. D., and SMALL, I. (2000). Imperfect competition and the dynamics of mark-ups, Bank of England Working Paper 110.

CALVO, G. (1983). Staggered Contracts in a Utility Maximizing Framework, Journal of Monetary Economics. 12, pp. 383-398.

FACCINI, R., MILLARD, S. and ZANETTI, F. (2010). Wage rigidities in an estimated DSGE model of the UK labour market, Bank of England, January 2010.

FAGGiO, F. (2006). Job Destruction, Job Creation and Unemployment in Transition Countries: What can we learn?, Centre for Economic Performance, London School of Economics and Political Science.

FLEK, V., VECERNIK, J. (2005). The Labour Market in the CR: Trends, Policies and Attitudes, Czech Journal of Economics and Finance, 55. 
GALÍ, J., GERTLER, M. (1999). Inflation Dynamics: A Structural Econometric Analysis. Journal of Monetary Economics.44, pp. 195-222.

HERBER, P. (2009). Estimating potential output: DSGE approach, Master Thesis, Masaryk University, Faculty of Science, Brno

HLOUSEK, M. (2008). Nominal Rigidities and Wage-Price Dynamics in Estimated DSGE Model: Application for the Czech Economy, Research Centre for Competitiveness of Czech Economy, Working Paper 28/2008.

CHRISTOFFEL, K., COENEN, G., WARNE, A. (2008). The New Area-Wide Model of the Euro Area: A Micro-Founded Open-Economy Model for Forecasting and Policy Analysis, European Central Bank, Working Paper No. 944

CHRISTOFFEL, K. COSTAIN, J., de WALQUE, G., KUESTER, K. LINZERT, T., MILlARD, S., PIERRARD, O. (2009). Inflation Dynamics with Labour Market Matching: Assessing Alternative Specifications, Research Department, Federal Reserve Bank of Philadelphia, Working paper No. 09-6.

KRAUSE, M., LUBIK, T. A. (2007). The (ir)relevance of real wage rigidity in the New Keynesian model with search frictions, Journal of Monetary Economics. Volume 54, Issue 3, pp. 706-727. DOI: 10.1016/j.jmoneco.2005.12.001

KRAUSE, M., LOPEZ-SALIDO, D. J., LUBIK, T. A. (2008a). Inflation Dynamics with Search Frictions: A Structural Econometric Analysis. Journal of Monetary Economics, 55(5), 892-916. DOI:10.1016/j.jmoneco.2008.04.004

MUSIL, K., VAŠÍČEK, O. (2006). Behavior of the Czech Economy: New Open Economy Macroeconomics DSGE Model, Brno, CVKSCE MU, Working Paper No. 23, ISSN 1801-4496.

NICKELL, S. (1997). Unemployment and Labor Market Rigidities: Europe versus North America, Journal of Economic Perspectives. 11, 55-74.

REMO, A. (2007). Expectations of monetary policy rules and inflation targeting in an open economy(DSGE model approach), Master Thesis, Masaryk University, Faculty of Economics and Administration, Brno

THOMAS, C. (2008).: Search and Matching Frictions and Optimal Monetary Policy, Journal of Monetary Economics, 55, 936-956. DOI:10.1016/j.jmoneco.2008.03.007

TRIGARI, A. (2006). The Role of Search Frictions and Bargaining for Inflation Dznamics, Working Paper 304, IGIER (Innocenzo Gasparini Institute for Economic Research), Bocconi University

GALÍ, J., GERTLER, M., LÓPEZ-SALIDO, J. D. (2005). Robustness of the Estimates of the Hybrid New Keynesian Phillips Curve. (first draft: June 2001), Retrieved Ferbuary 2, 2009 from http://www.nyu.edu/econ/user/gertlerm/robustness.pdf. 


\section{Appendix A}

\section{Derivation of the wage Phillips Curve}

A first order Taylor expansion on eq. (26) yields:

$$
E_{t} \sum_{s=0}^{\infty} \beta^{s}(1-\rho)^{s} \delta_{w}^{s}\left(\log \omega_{j t}^{*} h_{j t+s} \log \omega h-\hat{\omega}_{j t+s \mid t}^{t a r}\right)=0
$$

It is noticeable in eq. (27) that $\hat{\omega}_{j t}^{t a r}=\hat{\omega}_{t}^{t a r}$. If $\hat{\omega}_{j t}^{t} a r=\hat{\omega}_{t}^{t} a r$, then eq. (26) implies $\omega_{j t}^{*}=\omega_{t}^{*}$

Eq. (39) can be rewritten and solved for $\omega_{t}^{*}$, and they express the solution recursively:

$$
\log \omega_{t}^{*}=\left[1-\beta(1-\rho) \delta_{w}\right]\left(\hat{\omega}_{t}^{t a r}-\log h_{t}+\log \omega h\right)+\beta(1-\rho) \delta_{w} E_{t} \log \omega_{t+1}^{*}(
$$

The low of motion of the wage index in eq. (28) can be rewritten as:

$$
\log \omega_{t}^{*}-\log \omega_{t-1}=\pi_{w t},
$$

where $\pi_{w t}=\log \omega_{t}-\log \omega_{t-1}$. Now the eq. (39) is rewritten by using eq. (41) as:

$$
\pi_{w t}=k_{w}\left(\hat{\omega}_{t}^{t a r}-\hat{\omega}_{t}-\hat{h}_{t}\right)+\beta(1-\rho) E_{t} \pi_{w t+1},
$$

where $k_{w}=\left[1-\beta(1-\rho) \delta_{w}\right]\left(1-\delta_{w}\right) / \delta_{w}$. 


\section{Appendix B}

The log-linear equilibrium conditions

Euler equations

$$
\begin{gathered}
\hat{\lambda}_{t}=\hat{\lambda}_{t+1}+r_{t}-\pi_{t+1} \\
\hat{\lambda}_{t}=\zeta_{t}-[\sigma(1-\varsigma)]\left(\hat{c}_{t}-\hat{c}_{t-1}\right) \\
\hat{\lambda}_{t}=\hat{\lambda}_{t+1}+\beta(1-\alpha) \frac{\varphi}{\lambda} \frac{y}{k}\left(\hat{\varphi}_{t+1}-\hat{\lambda}_{t+1}+\hat{y}_{t+1}-\hat{k}_{t+1}\right)
\end{gathered}
$$

Production function

$$
\hat{y}_{t}=\hat{A}_{t}+\alpha\left(\hat{n}_{t}+\hat{h}_{t}\right)+(1-\alpha) \hat{k}_{t}
$$

Resource constraint

$$
\hat{y}_{t}=\left(\frac{c}{y}\right) \hat{c}_{t}+\frac{\varepsilon_{c} a v^{\varepsilon_{c}}}{y} \hat{v}_{t}+\frac{i}{y} \hat{i}_{t}+\frac{g}{y} \hat{g}_{t}
$$

Unemployment

$$
\hat{u}_{t}=-(1-\rho) \frac{n}{u} \hat{n}_{t-1}
$$

Employment

$$
\hat{n}_{t}=(1-\rho) \hat{n}_{t-1}+\rho\left[\xi \hat{u}_{t}+(1-\xi) \hat{v}_{t}\right]
$$

Government spending

$$
\hat{g}_{t}=\frac{b^{*} n * \hat{n}_{t}}{g}+\frac{t * \hat{t}_{t}}{g}
$$

Tightness

$$
\hat{\theta}_{t}=\hat{v}_{t}-\hat{u}_{t}
$$

Investment

$$
\frac{i}{k} \hat{i}_{t}=\hat{k}_{t+1}-\left(1-\delta_{k}\right) \hat{k}_{t}
$$


Job Creation

$$
\begin{aligned}
& \frac{\varepsilon_{a v}{ }^{\varepsilon_{c-1}} \theta^{\xi}}{m}\left[\left(\varepsilon_{c}-1\right) \hat{v}_{t}+\xi \hat{\theta}_{t}\right]=\alpha \frac{\varphi}{\lambda} \frac{y}{n}\left(\hat{\varphi}_{t}-\hat{\lambda}_{t}+\hat{y}_{t}-\hat{n}_{t}\right)-\omega h\left(\hat{\omega}_{t}+\hat{h}_{t}\right) \\
& +(1-\rho) \beta \frac{\varepsilon_{c} a v^{\varepsilon^{c}-1} \theta^{\xi}}{m}\left[\left(\varepsilon_{c}-1\right) \hat{v}_{t+1}+\xi \hat{\theta}_{t+1}+\hat{\lambda}_{t+1}-\hat{\lambda}_{t}\right]
\end{aligned}
$$

Target wage bill

$$
\begin{aligned}
& \hat{\omega}_{t}^{t} a r=\frac{1}{\omega h} \quad\left[\eta \varphi m p e\left(\hat{\varphi}_{t}+\hat{m} p e_{t}\right)+(1-\eta) \frac{h^{1+\mu}}{1+\mu} \frac{1}{\lambda}\left(\hat{\zeta}_{t}+\hat{\chi}_{t}-\hat{\lambda}_{t}+(1+\mu) \hat{h}_{t}\right)\right] \\
& +\eta(1-\rho) \beta \varepsilon_{c} a v^{\varepsilon_{c-1}} \theta\left[\hat{\lambda}_{t+1}-\hat{\lambda}_{t}+\hat{\theta}_{t+1}+\left(\varepsilon_{c}-1\right) \hat{v}_{t+1}\right]
\end{aligned}
$$

Hours

$$
\hat{h}_{t}=\frac{1}{(1+\mu-\alpha)}\left[\hat{\varphi}_{t}+\hat{A}_{t}+(\alpha-1) \hat{n}_{t}+(1-\alpha) \hat{k}_{t}+\hat{\lambda}_{t}-\hat{\zeta}_{t}-\hat{\chi}_{t}\right]
$$

Marginal product of employment

$$
\hat{m} p e_{t}=\hat{A}_{t}+(1-\alpha)\left(\hat{k}_{t-1}-\hat{n}_{t}\right)+\alpha \hat{n}_{t}
$$

Average real wage

$$
\hat{\omega}_{t}-\hat{\omega}_{t-1}+\pi_{t}=\pi_{w t}
$$

Wage inflation

$$
\pi_{w t}=k_{w}\left(\hat{\omega}_{t}^{t a r}-\hat{\omega}_{t}-\hat{h}_{t}\right)+\beta \pi_{w t+1}
$$

Price inflation

$$
\pi_{t}=k_{p}\left(\hat{\varphi}_{t}+\hat{\varepsilon}_{t}\right)+\beta \pi_{t+1}
$$

Taylor rule

$$
r_{t}=\rho_{r} r_{t-1}+\left(1-\rho_{r}\right)\left(r_{\pi} \pi_{t}+r_{y} \hat{y}_{t}\right)+\hat{\varepsilon}_{t}^{R}
$$




\section{Appendix C}

Table 1: Fixed parameters for $\mathbf{C R}$

\begin{tabular}{|l|l|l|}
\hline Parameters & Description & Values \\
\hline$\beta$ & Discount factor & 0.99 \\
\hline$\alpha$ & Labor share & 0.66 \\
\hline$\delta_{k}$ & Capital depreciation rate & 0.025 \\
\hline$\zeta$ & Habit persistence & 0.75 \\
\hline$\varepsilon_{c}$ & Elasticity of the vacancy cost function & 1.10 \\
\hline
\end{tabular}

Source: our estimate

Table 2: Prior and Posterior Distribution of Structural Parameters distributions for CR

\begin{tabular}{|c|c|c|c|c|c|c|c|}
\hline - & Description & Prior & Post. & Confid & nce int. & Prior & $\begin{array}{c}\text { Prior } \\
\text { SD }\end{array}$ \\
\hline$\sigma$ & Relative Risk Aversion & 1 & 0.99 & 0.9 & 1.06 & gamma & 0.05 \\
\hline$\mu$ & Inverse Frish elasticity & 1.9 & 2.1586 & 1.9533 & 2.2672 & gamma & 0.1 \\
\hline$\xi$ & $\begin{array}{l}\text { Matching function } \\
\text { elasticity }\end{array}$ & 0.42 & 0.2874 & 0.0775 & 0.5276 & beta & 0.2 \\
\hline$a$ & $\begin{array}{l}\text { Const. vacancy cost } \\
\text { function }\end{array}$ & 6 & 5.3820 & 3.9192 & 6.4729 & gamma & 1 \\
\hline$m$ & $\begin{array}{l}\text { Constant matching } \\
\text { function }\end{array}$ & 1 & 1.0764 & 0.9479 & 1.2426 & gamma & 0.1 \\
\hline$b$ & Unemployment benefits & 0.53 & 0.5560 & 0.4715 & 0.6853 & beta & 0.1 \\
\hline$\rho$ & Job destruction rate & 0.05 & 0.0512 & 0.0370 & 0.0668 & beta & 0.01 \\
\hline$\delta_{w}$ & Calvo wage parameter & 0.75 & 0.7732 & 0.6227 & 0.9012 & beta & 0.1 \\
\hline$\delta_{p}$ & Calvo price parameter & 0.6 & 0.6021 & 0.4795 & 0.7726 & beta & 0.1 \\
\hline$r_{\pi}$ & $\begin{array}{l}\text { Taylor rule resp. to } \\
\text { inflation }\end{array}$ & 1.5 & 1.5234 & 1.4551 & 1.5941 & gamma & 0.05 \\
\hline$r_{y}$ & $\begin{array}{c}\text { Taylor rule resp. to } \\
\text { output }\end{array}$ & 0.5 & 0.6867 & 0.6073 & 0.7649 & gamma & 0.05 \\
\hline$\rho_{r}$ & Taylor rule inertia & 0.5 & 0.5313 & 0.5039 & 0.5601 & beta & 0.02 \\
\hline$\eta$ & $\begin{array}{l}\text { Bargaining power } \\
\text { parameter }\end{array}$ & 0.5 & 0.5011 & 0.3508 & 0.6454 & beta & 0.1 \\
\hline
\end{tabular}

Source: our estimate 
Table 3: Prior and Posteriors Distribution of Shock Parameters for CR

\begin{tabular}{|c|c|c|c|c|c|c|c|}
\hline- & Description & $\begin{array}{l}\text { Prior } \\
\text { mean }\end{array}$ & $\begin{array}{l}\text { Post. } \\
\text { mean }\end{array}$ & \multicolumn{2}{|c|}{ Confidence int. } & $\begin{array}{c}\text { Prior } \\
\text { dist }\end{array}$ & $\begin{array}{c}\text { Prior } \\
\text { SD }\end{array}$ \\
\hline \multicolumn{8}{|c|}{ Autoregressive parameters: } \\
\hline$\rho_{\chi}$ & Labor supply & 0.8 & 0.9995 & 0.9992 & 1.0000 & beta & 0.2 \\
\hline$\rho_{\zeta}$ & Preferences & 0.8 & 0.9999 & 0.9998 & 1.0000 & beta & 0.2 \\
\hline$\rho_{\varepsilon}$ & Mark-up & 0.8 & 0.9952 & 0.9884 & 0.9999 & beta & 0.2 \\
\hline$\rho_{a}$ & Technology & 0.8 & 0.9637 & 0.9242 & 1.0000 & beta & 0.2 \\
\hline \multicolumn{8}{|c|}{ Shock parameters: } \\
\hline$\sigma_{\mathrm{a}}$ & Technology & 0.002 & 0.0234 & 0.0161 & 0.0311 & invg & 0.9250 \\
\hline$\sigma_{\zeta}$ & Preferences & 0.002 & 0.0017 & 0.0005 & 0.0029 & invg & 0.9250 \\
\hline$\sigma_{\varepsilon}$ & Mark-up & 0.002 & 0.0701 & 0.0541 & 0.0029 & invg & 0.9250 \\
\hline$\sigma_{\chi}$ & Labor supply & 0.002 & 0.1684 & 0.1040 & 0.3356 & invg & 0.9250 \\
\hline$\sigma_{\dot{\varepsilon}}$ & Monetary policy & 0.002 & 0.0269 & 0.0226 & 0.0307 & invg & 0.9250 \\
\hline
\end{tabular}

Source: our estimate

Table 4: Fixed parameters for Austria

\begin{tabular}{|l|l|l|}
\hline Parameters & Description & Values \\
\hline$\beta$ & Discount factor & 0.988 \\
\hline$\alpha$ & Labor share & 0.66 \\
\hline$\delta_{k}$ & Capital depreciation rate & 0.02 \\
\hline $\boldsymbol{S}$ & Habit persistence & 0.5 \\
\hline $\mathcal{E}_{c}$ & Elasticity of the vacancy cost function & 1.10 \\
\hline
\end{tabular}

Source: our estimate 
Table 5: Prior and Posterior Distribution of Structural Parameters distributions for Austria

\begin{tabular}{|c|c|c|c|c|c|c|c|}
\hline- & Description & $\begin{array}{l}\text { Prior } \\
\text { mean }\end{array}$ & $\begin{array}{l}\text { Post. } \\
\text { mean }\end{array}$ & Confic & nce int. & $\begin{array}{c}\text { Prior } \\
\text { dist }\end{array}$ & $\begin{array}{l}\text { Prior } \\
\text { SD }\end{array}$ \\
\hline$\sigma$ & $\begin{array}{l}\text { Relative Risk } \\
\text { Aversion }\end{array}$ & 1 & 0.9947 & 0.9288 & 1.0597 & gamma & 0.05 \\
\hline$\mu$ & $\begin{array}{l}\text { Inverse Frish } \\
\text { elasticity }\end{array}$ & 2 & 2.2313 & 2.0796 & 2.3962 & gamma & 0.1 \\
\hline$\xi$ & $\begin{array}{l}\text { Matching function } \\
\text { elasticity }\end{array}$ & 0.6 & 0.4620 & 0.2562 & 0.7003 & beta & 0.2 \\
\hline$a$ & $\begin{array}{l}\text { Const. vacancy } \\
\text { cost function }\end{array}$ & 6 & 4.5529 & 3.2512 & 5.6238 & gamma & 1 \\
\hline$m$ & $\begin{array}{l}\text { Constant matching } \\
\text { function }\end{array}$ & 1 & 1.0219 & 0.8491 & 1.1742 & gamma & 0.1 \\
\hline$b$ & $\begin{array}{l}\text { Unemployment } \\
\text { benefits }\end{array}$ & 0.5 & 0.5015 & 0.3436 & 0.6482 & beta & 0.1 \\
\hline$\rho$ & $\begin{array}{l}\text { Job destruction } \\
\text { rate }\end{array}$ & 0.03 & 0.0464 & 0.0336 & 0.0661 & beta & 0.01 \\
\hline$\delta_{w}$ & $\begin{array}{l}\text { Calvo wage } \\
\text { parameter }\end{array}$ & 0.6 & 0.6079 & 0.4559 & 0.7772 & beta & 0.1 \\
\hline$\delta_{p}$ & $\begin{array}{l}\text { Calvo price } \\
\text { parameter }\end{array}$ & 0.6 & 0.5880 & 0.4438 & 0.7791 & beta & 0.1 \\
\hline $\mathcal{E}$ & $\begin{array}{l}\text { Elasticity of } \\
\text { demand }\end{array}$ & 11 & 10.8628 & 8.7887 & 12.5565 & gamma & 1 \\
\hline$r_{\pi}$ & $\begin{array}{l}\text { Taylor rule resp. to } \\
\text { inflation }\end{array}$ & 1.7 & 1.6954 & 1.6133 & 1.7612 & gamma & 0.05 \\
\hline$r_{y}$ & $\begin{array}{l}\text { Taylor rule resp. to } \\
\text { output }\end{array}$ & 0.2 & 0.5577 & 0.4502 & 0.6698 & gamma & 0.05 \\
\hline$\rho_{r}$ & Taylor rule inertia & 0.85 & 0.8126 & 0.7828 & 0.8471 & beta & 0.02 \\
\hline$\eta$ & $\begin{array}{l}\text { Bargaining power } \\
\text { parameter }\end{array}$ & 0.5 & 0.5040 & 0.3748 & 0.6420 & beta & 0.1 \\
\hline
\end{tabular}

\footnotetext{
Source: our estimate
} 
Table 6: Prior and Posteriors Distribution of Shock Parameters for Austria

\begin{tabular}{|c|c|c|c|c|c|c|c|c|}
\hline- & Description & $\begin{array}{c}\text { Prior } \\
\text { mean }\end{array}$ & $\begin{array}{c}\text { Post. } \\
\text { mean }\end{array}$ & \multicolumn{2}{|l|}{ Confidence int. } & $\begin{array}{c}\text { Prior } \\
\text { dist }\end{array}$ & $\begin{array}{c}\text { Prior } \\
\text { SD }\end{array}$ \\
\hline \multicolumn{2}{|c|}{ Autoregressive parameters: } & \multicolumn{5}{|l|}{} \\
\hline$\rho_{\chi}$ & Labor supply & 0.8 & 0.9390 & 0.7771 & 0.9997 & beta & 0.14 \\
\hline$\rho_{\zeta}$ & Preferences & 0.8 & 0.8262 & 0.7248 & 0.9961 & beta & 0.14 \\
\hline$\rho_{\varepsilon}$ & Mark-up & 0.8 & 0.9797 & 0.9642 & 0.9939 & beta & 0.14 \\
\hline$\rho_{a}$ & Technology & 0.8 & 0.6355 & 0.5593 & 0.6883 & beta & 0.14 \\
\hline \multicolumn{2}{|c|}{ Shock parameters: } & & & & & \\
\hline$\sigma_{\mathrm{a}}$ & Technology & 0.600 & 0.1289 & 0.0937 & 0.1567 & invg & 2.00 \\
\hline$\sigma_{\zeta}$ & Preferences & 0.600 & 0.2222 & 0.1646 & 0.2789 & invg & 2.00 \\
\hline$\sigma_{\varepsilon}$ & Mark-up & 0.600 & 0.1098 & 0.0892 & 0.1323 & invg & 2.00 \\
\hline$\sigma_{\chi}$ & Labor supply & 2.000 & 0.3968 & 0.3202 & 0.4551 & invg & 2.00 \\
\hline$\sigma_{\tilde{\varepsilon}}$ & Monetary policy & 1.000 & 0.1295 & 0.1290 & 0.1299 & invg & 2.00 \\
\hline
\end{tabular}

Source: our estimate 


\section{Appendix D}

Figure 1: Impulse Response for Technology shock
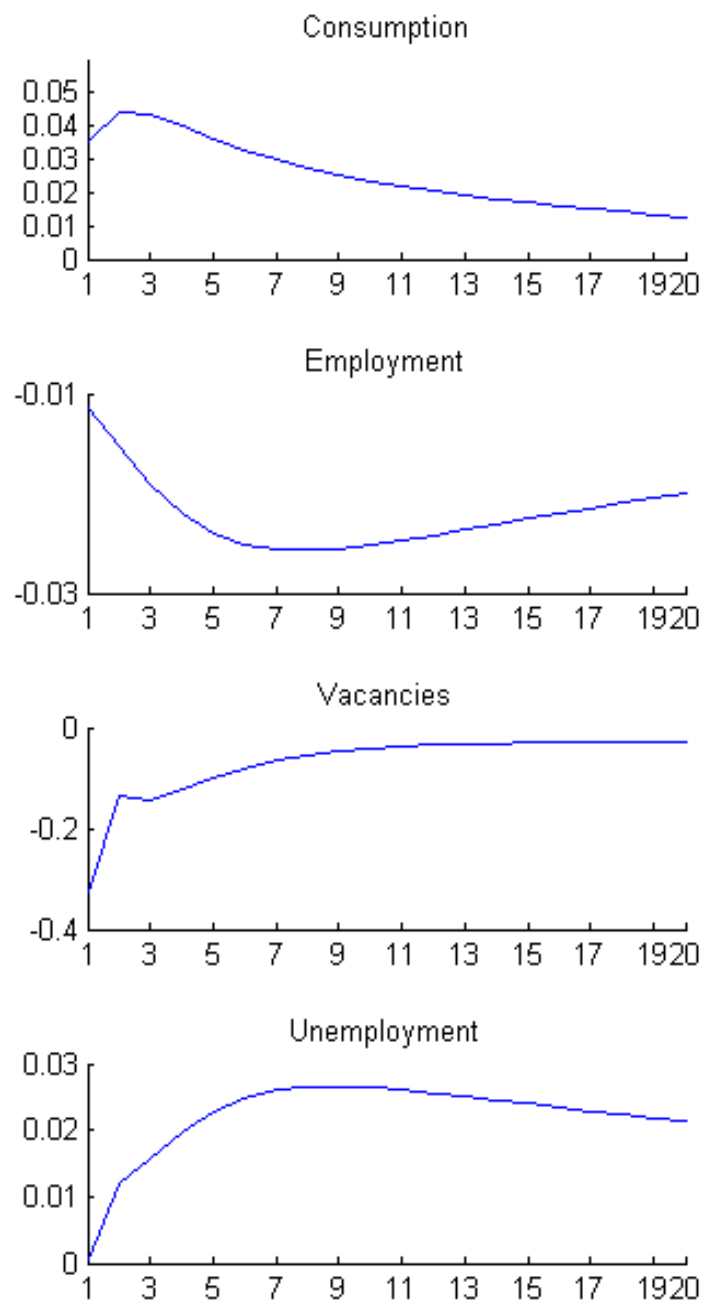

Source: our estimate 
Hours

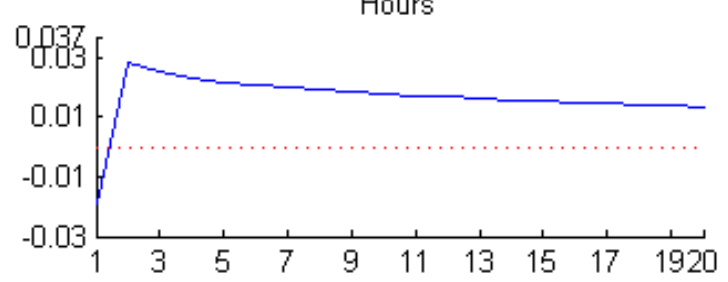

Wage inflation

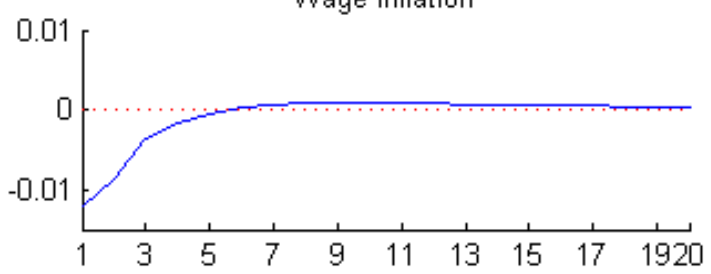

Real Wage

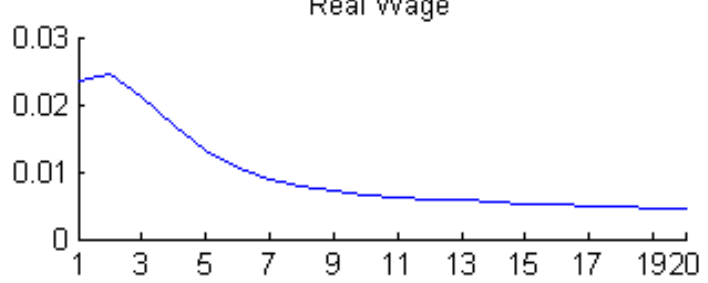

Tightness

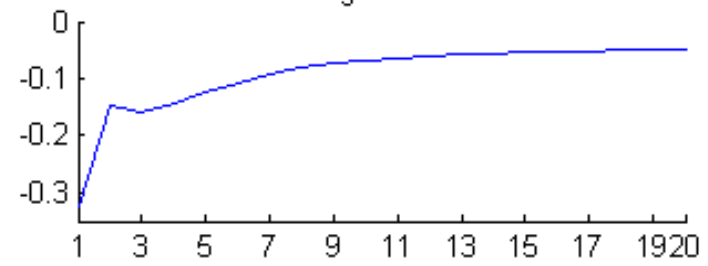

Source: our estimate 

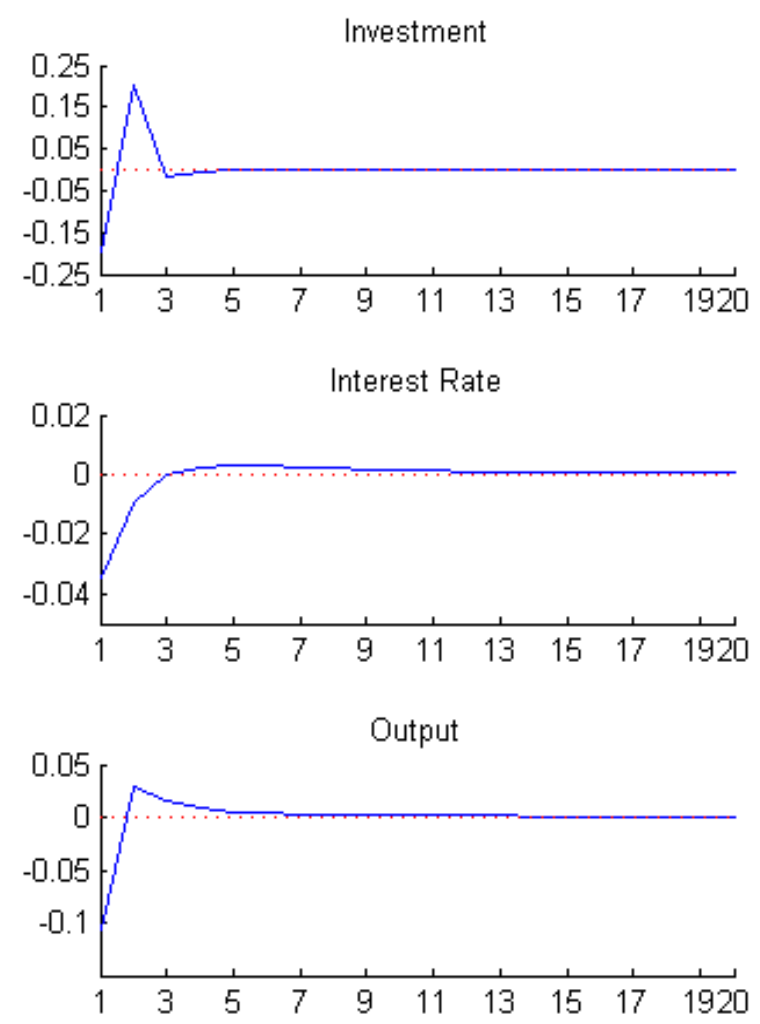

Source: our estimate 